DOI: 10.12731/2227-930X-2020-4-189-196

УДК 004.94

\title{
ПРОБЛЕМЫ АВТОМАТИЗАЦИИ \\ УПРАВЛЕНИЯ ЧЕЛОВЕЧЕСКИМИ РЕСУРСАМИ НА ТРАНСПОРТНОМ ПРЕДПРИЯТИИ
}

Львович Я.Е., Преображенский А.П., Чопоров О.Н.

В статье рассматриваются особенности формирования информационно-советующей системы транспортного предприятия. Показано, каким образом можно использовать систему поддержки принятия решений.

Ключевые слова: система перевозок; автоматизация; управление; система.

\section{THE PROBLEMS OF AUTOMATION OF HUMAN RESOURCES MANAGEMENT IN A TRANSPORTATION COMPANY}

\section{Lvovich Ya.E., Preobrazhenskiy A.P., Choporov O.N.}

The paper discusses the features of the formation of an information-advising system of a transport company. It is shown how the decision support system can be used.

Ключевые слова: transportation system; automation; control; system.

\section{Введение}

Поскольку в настоящее время существуют требований, связанные с функциональностью объектов управления персоналом внутри транспортных предприятий. При этом должно быть полное соответствие современных автоматизированных систем самым разным запросам пользователей $[1,2]$. 
Исходя из осуществленного анализа по задачам, которые решаются на основе систем управления персоналом, можно сделать вывод о том, что весьма многие из них могут анализироваться на базе систем поддержки принятия решений (СППР). Это относится к разным практическим приложениям в сфере оперативного управления персоналом [3, 4].

Среди задач, которые востребованы с точки зрения решений можно указать определение характеристик конфликта на основе целей управления. Анализируются социальные и производственные конфликты внутри транспортного предприятия [5, 6].

Каким образом можно анализировать конфликт? Как условный признак сложности ситуации. Тогда будут выводиться меры и средства, которые требуются с тем, чтобы осуществлять разрешение и устранение конфликтов. Руководители организации в ходе рассмотрении характеристик конфликтов исходят из того, какой у них опыт подобных конфликтных ситуаций. Будет происходить определение формы конфликта на базе соответствующих факторов, которые характеризуют ситуацию. Но, в результате анализа статистических данных можно убедиться, что достаточно большое значение вероятности ошибки руководителей, когда определяется форма конфликта. При этом ориентируются на рамки субъективных предпочтений. При определении характеристик по конфликтам на производстве с тем, чтобы осуществить снижение вероятностей ошибок и уменьшить время по принятию решений, в данной работе даются предложения по разработке СППР по определению форм конфликта. Она базируется на том, чтобы использовать знания руководителей компании или служб управления персоналом, которые характеризуются большим опыт в ходе разрешении конфликтов.

\section{Особенности формирования информационно-советующей системы транспортного предприятия.}

Можно представлять функциональную структуру информационно-советующей системы, связанной с поддержкой принятия ре- 
шений как совокупность нескольких ключевых модулей, которые приведены на рис. 1.

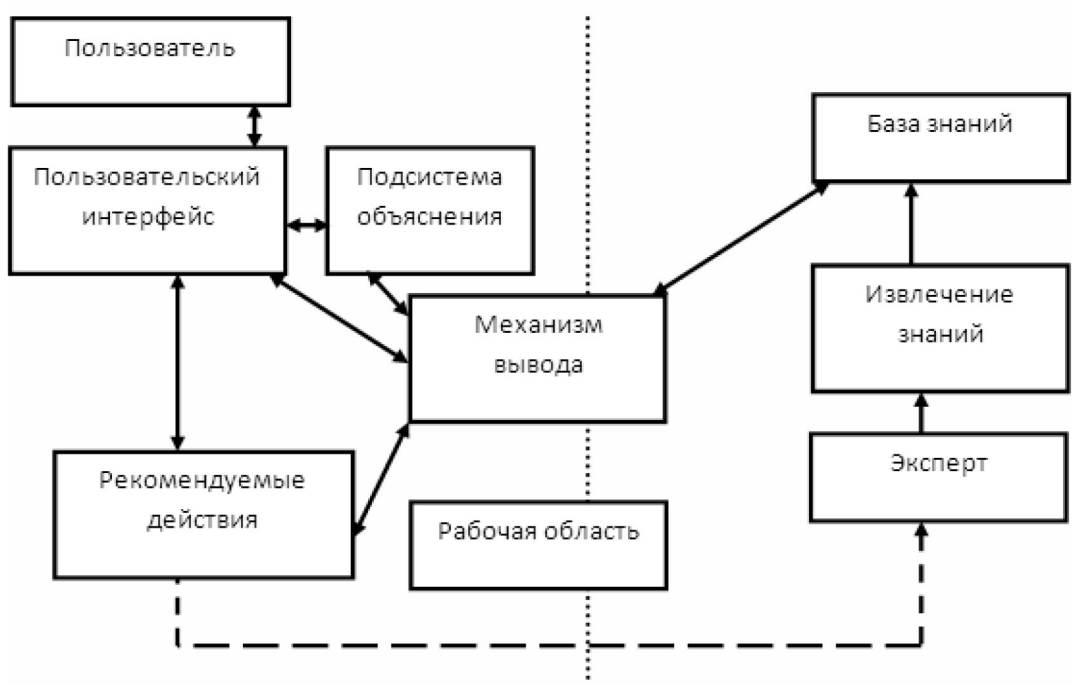

Рис. 1. Иллюстрация структуры СППР и ее окружения

Среди модулей можно указать подсистему, связанную с извлечением знаний. Также есть база знаний. Предусмотрен механизм вывода. Разработан пользовательский интерфейс. Есть рабочая область. Создана подсистема объяснения. Первая подсистема связана с тем, что накапливаются, передаются и преобразуются экспертизы решения задачи. Они идут от экспертов или документированных источников знаний $[7,8]$. Это осуществляется при помощи компьютерной программы. При этом важно вести конструирование или расширения базы знаний. В базах знаний содержатся знания. Их формируют с тем, чтобы понимать, формулировать и решать задачи. В нее входят два ключевых компонента. Они являются фактами, а также специальными эвристиками. Механизмы вывода, характеризуются при помощи стандартных правил реше- 
ния задач. Выражение неформальных знаний происходит на базе эвристик. Глобальные стратегии существуют в базах знаний. Они могут рассматриваться как эвристики. Внутри экспертных систем как первоначальный необработанный материал анализируются знания. Механизм вывода рассматривается как центр СППР. Он считается в виде управляющей структуры. Базирование происходит при помощи правил. Это наблюдается во многих компьютерных программах. В результате можно оценить характеристики информации. Из этого вытекают условия по применению знаний системы. На чем базируется механизм вывода? Он связан с интерпретатором и планировщиком. В пользовательском интерфейсе СППР содержится языковой процессор. Процесс общения основывается на естественном языке. Рабочая область располагается отдельным образом. В подсистеме объяснения есть возможности для отслеживания ответственности по соответствию заключений их источникам.

\section{Использование СППР на транспортном предприятии}

Основываясь на вышесказанном, схему работы можно СППР в ходе процессов управления социальными и производственными конфликтами описать при помощи такой блок-схемы (рис. 2):

В качестве важной исходной информации, когда разрабатывается СППР можно считать модели объекта. В существующих условиях все применяемые подходы в области моделирования объектов относятся к одному множеству методов, позволяющих моделировать сложные информационные системы $[9,10]$. Укажем те подходы, которые являются достаточно известными.

1) Проведение структурного анализа и структурного проектирования.

2) Использование методики IDEF.

3) Использование методики SADT.

4) Применение элементов объектно-ориентированного подхода (ООП).

5) Применение интегрированных подходов в ходе разработок моделей. 


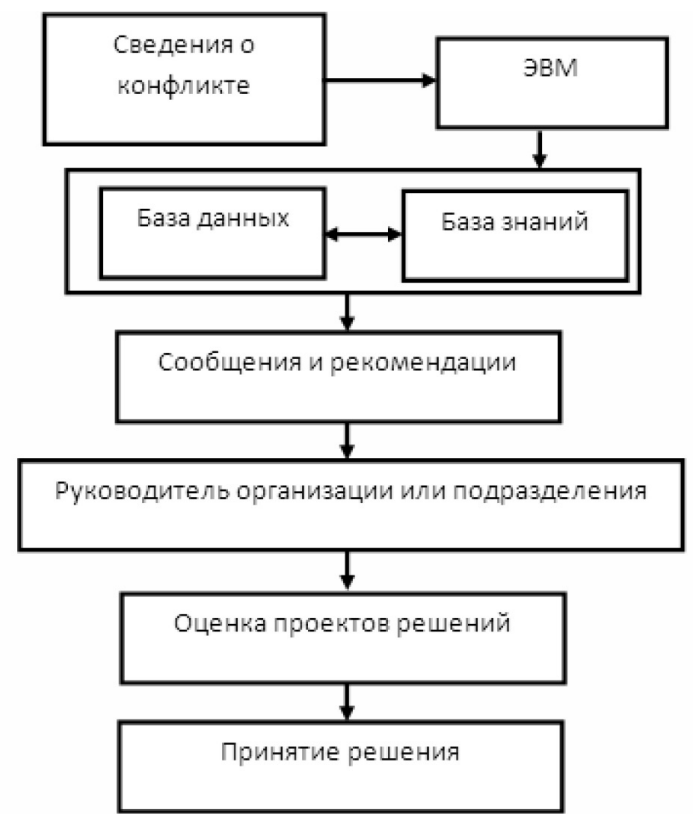

Рис. 2. Иллюстрация блок-схемы функционирования СППР в ходе управления конфликтами

\section{Выводы}

Из проведенного анализа было установлено, что существующие системы не в полной мере могут считаться удовлетворяющими современным требованиям. Достаточно четким способом формулировка есть по подходам для формирования современных систем управления персоналом. При этом плодотворным считается использование подходов по созданию интеллектуальных систем, внутри которых есть СППР. В работе показаны возможности применения СППР для управления конфликтами.

Информация о конфликте интересов. Авторы заявляют об отсутствии конфликта интересов.

Информация о спонсорстве. Исследование не имело финансовой поддержки. 


\section{Список литературы}

1. Паневин Р.Ю., Преображенский Ю.П. Задачи оптимального управления многостадийными технологическими процессами // Вестник Воронежского института высоких технологий. 2010. № 6. C. $77-80$.

2. Преображенский Ю.П. Информационные технологии, используемые в сфере менеджмента // Вестник Воронежского института высоких технологий. 2018. № 2 (25). С. 43-46.

3. Ермолова В.В., Преображенский Ю.П. Методика построения семантической объектной модели // Вестник Воронежского института высоких технологий. 2012. № 9. С. 87-90.

4. Преображенский Ю.П., Коновалов В.М. Анализ подходов к формированию рекомендательных систем // Вестник Воронежского института высоких технологий. 2019. № 4 (31). С. 88-90.

5. Преображенский Ю.П., Коновалов В.М. О методах создания рекомендательных систем //Вестник Воронежского института высоких технологий. 2019. № 4 (31). С. 75-79.

6. Берман Н.Д., Белов А.М. Общественный транспорт и инновации // International Journal of Advanced Studies. 2019. Т. 9. № 2. C. 7-13.

7. Шакиров А.А., Зарипова Р.С. Особенности моделирования логистических систем // International Journal of Advanced Studies. 2019. T. 9. № 4. C. 27-31.

8. Сапожникова С.М. Корпоративное управление в железнодорожном транспорте // International Journal of Advanced Studies. 2019. T. 9. № 4. C. 19-42.

9. Лысанов Д.М., Бикмухаметова Л.Т. Анализ показателей качества и конкурентоспособности оборудования // International Journal of Advanced Studies. 2018. T. 8. № 4-2. C. 50-55.

10. Преображенский Ю.П. Построение складской структуры предприятия // В сборнике: Молодежь и системная модернизация страны Сборник научных статей 3-й Международной научной конференции студентов и молодых ученых. В 4-х томах. Ответственный редактор А.А. Горохов. 2018. С. 286-290. 


\section{References}

1. Panevin R.Yu., Preobrazhenskij Yu.P. Zadachi optimal'nogo upravleniya mnogostadijnymi tekhnologicheskimi processami // Vestnik Voronezhskogo instituta vysokih tekhnologij. 2010. № 6. S. $77-80$.

2. Preobrazhenskij Yu.P. Informacionnye tekhnologii, ispol'zuemye v sfere menedzhmenta // Vestnik Voronezhskogo instituta vysokih tekhnologij. 2018. № 2 (25). S. 43-46.

3. Ermolova V.V., Preobrazhenskij Yu.P. Metodika postroeniya semanticheskoj ob»ektnoj modeli // Vestnik Voronezhskogo instituta vysokih tekhnologij. 2012. № 9. S. 87-90.

4. Preobrazhenskij Yu.P., Konovalov V.M. Analiz podhodov k formirovaniyu rekomendatel'nyh sistem // Vestnik Voronezhskogo instituta vysokih tekhnologij. 2019. № 4 (31). S. 88-90.

5. Preobrazhenskij YU.P., Konovalov V.M. O metodah sozdaniya rekomendatel'nyh sistem //Vestnik Voronezhskogo instituta vysokih tekhnologij. 2019. № 4 (31). S. 75-79.

6. Berman N.D., Belov A.M. Obshchestvennyj transport i innovacii // International Journal of Advanced Studies. 2019. T. 9. № 2. S. 7-13.

7. Shakirov A.A., Zaripova R.S. Osobennosti modelirovaniya logisticheskih sistem // International Journal of Advanced Studies. 2019. T. 9. № 4. S. 27-31.

8. Sapozhnikova S.M. Korporativnoe upravlenie v zheleznodorozhnom transporte // International Journal of Advanced Studies. 2019. T. 9. № 4. S. $19-42$.

9. Lysanov D.M., Bikmuhametova L.T. Analiz pokazatelej kachestva i konkurentosposobnosti oborudovaniya // International Journal of Advanced Studies. 2018. T. 8. № 4-2. S. 50-55.

10. Preobrazhenskij Yu.P. Postroenie skladskoj struktury predpriyatiya // V sbornike: Molodezh' i sistemnaya modernizaciya strany Sbornik nauchnyh statej 3-j Mezhdunarodnoj nauchnoj konferencii studentov i molodyh uchenyh. V 4-h tomah. Otvetstvennyj redaktor A.A. Gorohov. 2018. S. 286-290. 


\section{ДАННЫЕ ОБ АВТОРАХ}

Львович Яков Евсеевич, профессор, доктор технических наук Воронежский государственньй технический университет ул. 20 лет Октября, 84, Воронеж, 394006, РФ Komkovvivt@yandex.ru

Преображенский Андрей Петрович, профессор, доктор технических наук, доцент Воронежский институт высоких технологий ул. Ленина, 73a, Воронеж, 394043, РФ

Чопоров Олег Николаевич, профессор, доктор технических наук Воронежский государственный технический университет ул. 20 лет Октября, 84, Воронеж, 394006, РФ Komkovvivt@yandex.ru

\section{DATA ABOUT THE AUTHORS}

Lvovich Yakov Yevseevich, Doctor of Technical Sciences, Professor Voronezh State Technical University

84, 20 years of October Str., Voronezh, 394006, Russian Federation Komkovvivt@yandex.ru

ORCID: 0000-0002-7051-3763

Preobrazhenskiy Andrey Petrovich, Professor, Doctor of Technical Sciences, Associate Professor Voronezh Institute of High Technologies

73a, Lenin Str., Voronezh, 394043, Russian Federation

Komkovvivt@yandex.ru

ORCID: 0000-0002-6911-8053

Choporov Oleg Nikolaevich, Doctor of Technical Sciences, Professor Voronezh State Technical University

84, 20 years of October Str., Voronezh, 394006, Russian Federation Komkovvivt@yandex.ru

ORCID: 0000-0002-3176-499X 